yet been verified experimentally. Great interest is attached to the 'spectrum' of the rays incident on the earth's atmosphere, since they should give some light on a possible origin for the rays. It is rather remarkable to find that the spectrum of the rays can be represented roughly by a simple power law over a range of energy of above a million to one. More precisely, the number of rays with energy greater than some given value is roughly inversely proportional to the square of the energy, over the energy range from a thousand million to a thousand million million volts. It can scarcely be doubted that this remarkable law must have some profound, but at present unknown, cosmological significance.

\section{Fuel in Science and Practice}

THE monthly periodical Fuel in Science and Practice has completed eighteen volumes since it was launched as a supplement to the well-known mining journal Colliery Guardian. It was established on the initiative of the Coal Research Club in order to provide a medium of communication for those interested in the scientific study of fuel, and coal in particular. It was the first journal of its kind in the English language and has proved very suecessful, the success being doubtless due in a large measure to the efforts of its first editor, the late Prof. R. V. Wheeler. The first number of the nineteenth volume has now appeared under the editorship of Dr. R. Lessing, who has been associated with the venture since its inception. This, it may be taken, will ensure continuity of policy. It will continue to aim at providing a clearing-house for the results of investigations and a bridge between the science and practice of fuel technology.

The Institute of Fuel has decided to adopt Fuel as its research journal for the benefit of its members who wish to be kept informed of the results of recent investigations into coal and other combustibles. The Coal Research Club, assisted by an editorial commit. tee, will continue to direct its policy and ensure the maintenance of its old and successful traditions. It seems probable that the importance of fuel technology for some years to come will ensure a prosperous future for this journal. At the same time, it is pertinent to recall the unsatisfactory state of the documentation of science. While it appears relatively easy to publish journals containing interesting articles, the thankless task of publishing systematic abstracts is a growing burden the support of which meets steady reluctance.

\section{Coal-Gas and Fuel Research at Leeds}

Prow. D. T. A. Townend, who succeeded Prof. J. W. Cobb as head of the Department of Coal-gas and Fuel Industries and Livesey professor in the University of Leeds, has now issued his first report, covering the session 1938-39, to his Advisory Committee. He takes an opportunity therein to pay a tribute to the late Prof. Smithells, who died during the term under review and who was a member of the Committee from the time of its formation. To him also was due, more than to any other man, the formation of the Fuel Department in the University and, a few years later, the establishment of the Livesey chair by subscriptions from the gas industry.

In the body of the report, Prof. Townend reviews in turn the varied activities of his department, which has developed in severăal directions, not only fuel and gas engineering, but also the cognate subjects of refractory materials and metallurgy, in both of which teaching and research have made much headway. A post-graduate diploma in fuel and refractory materials has been instituted along similar lines to those already given in gas engineering and in fuel and metallurgy. The first opportunity will be taken to give a more systematic course in chemical engineering, which is, in effect, so largely the subject of the departmental teaching. Research continues to be supported by the gas industry and the Iron and Steel Institute. Prof. Townend is continuing work on flame, which had engaged him in London, and independent research work carried out by the staff and students continues to be a marked feature of the departmental activity.

\section{Modern Colour Printing}

IN the Electrical Review of February 2, an illustrated description is given of some of the new equipment installed by Geo. C. Caster and Co., Ltd., commercial and colour printers, who recently transferred their works to Cromwell Road, Peterborough. In accordance with modern practice the factory has been set out on a single floor, with a planned layout for the speedy handling of work and an uninterrupted continuity of production. There is no shafting, and individual direct electric drive is employed on all machines. One of the large high-speed letterpress machines is a two-revolution Miehle capable of a maximum output of 3,000 sheets, 25 in. by 40 in., per hour. Another large two-revolution machine takes bigger sheets ( 30 in. by 40 in.) and can print 2,300 sheets per hour. For small sheets up to $13 \frac{1}{2}$ in. by 20 in. vertical Miehle machines are brought into service. These'are specially suitable for high-class colour printing. A maximum of 4,500 prints an hour can be handled by each machine.

The use of a general lighting system of high intensity throughout the factory makes local lighting unnecessary (except under the machine boards). In the composing room an illumination intensity of $35 \mathrm{ft}$.-candles at the working plane is obtained with Benjamin reflectors, which are also used in the binding department to provide $10 \mathrm{ft}$.-candles. To facilitate the matching of ink colours, daylight reflectors have been installed in the machine department to give $14 \mathrm{ft}$.-candles.

\section{The Achromatic Lens}

THe contributions made to Lychnos during the last two years by Drs. N. V. E. Nordenmark and J. Nordstrom dealing with the invention of the achromatic lens and the part played by $\mathrm{S}$. Klingenstierna, professor of mathematics at the University of Uppsala, in the process, have been issued as a pamphlet by Almquist and Wiksells, Uppsala, with an English summary. Many of the original documents bearing 